\title{
Portal Venous and Aortic Glucose and Lactate Changes in a Chronically Catheterized Rat
}

\author{
ROBERT E. KIMURA, TIMOTHY R. LAPINE, AND W. MANFORD GOOCH III \\ Department of Pediatrics, School of Medicine, University of Utah, Salt Lake City, Utah 84132
}

\begin{abstract}
A method for portal venous, aortic, and gastric cannulation in the rat is described. Changes in mean portal venous and aortic blood glucose and lactate concentrations after an intragastric infusion of $\boldsymbol{d}$-glucose to chronically catheterized rats (after regaining preoperative weight) were compared to those of acutely catheterized rats $(1 \mathrm{~h}$ after catheter placement). Both portal venous and aortic catheters were patent for blood sampling in $67 \%$ of rats 8 days after catheter placement and $42 \%$ after 14 days. After intragastric infusion of $10 \mathrm{ml}$ of $0.29 \mathrm{M}$ dextrose, mean aortic blood glucose and lactate concentrations in chronically catheterized rats increased 80 and $73 \%$, respectively, $15 \mathrm{~min}$ after infusion and decreased to preinfusion concentrations by $60 \mathrm{~min}$. In acutely catheterized rats, mean aortic glucose and lactate concentrations increased linearly for $60 \mathrm{~min}$. The concentration differences between portal venous and aortic blood glucose and lactate concentrations in chronically catheterized rats were not significantly different than baseline differences. The portal venous glucose concentrations were significantly greater than aortic concentrations in acutely catheterized rats 15 , 30 , and $\mathbf{4 5} \mathrm{min}$ after the glucose infusion when compared to baseline differences. These data suggest that the rate of glucose uptake and metabolism to lactate is significantly altered in acutely catheterized rats when compared to chronically catheterized animals. (Pediatr Res 23: 235240, 1988)
\end{abstract}

\section{Abbreviation}

AVC, area under the curve.

Parenteral nutrition is commonly used in treating low birth weight infants. The intestine and its metabolic function is bypassed with parenteral nutrition. If the intestine is primarily an absorptive organ in which nutrients are absorbed intact, this therapy may be appropriate. However, perfused rat small intestine (1) as well as in situ perfused rat jejunal segments (2) metabolize glucose to lactate under aerobic conditions. Another significant end product of intestinal glucose metabolism is alanine (2). These end products are important liver gluconeogenic and glycogen precursors. Thus, the intestine may alter absorbed nutrients before transfer to the liver via the portal vein. Interpretation of the studies involved with intestinal metabolism are confounded by the concomitant effects of anesthesia and surgery. For instance, ether induces an increase in blood glucose and lactate concentrations (3) and alters pituitary-adrenal function

Received July 24, 1987; accepted October 14, 1987.

Correspondence and reprint requests Robert E. Kimura, Department of Pediatrics, University of Utah Medical Center, 50 North Medical Drive, Salt Lake City, UT 84132.

Supported in part by NIH Grant 2 R01 HD 18517-04.
(4); manual manipulation of the bowel can alter mesenteric blood flow and anesthesia can alter mesenteric blood flow and intestinal perfusion (5). These factors can alter intestinal perfusion and oxygen delivery. In contrast, studies that use the technique of chronic catheterization avoid these artifacts (6).

We have developed a rat model in which the portal vein, aorta, and stomach are catheterized chronically. Using this preparation, we serially determined in vivo portal venous and aortic blood concentrations of glucose, lactate, and alanine after a bolus intragastric infusion of glucose in nonstressed animals. We also determined the effects of surgery and anesthesia on portal venous and aortic blood glucose, lactate, and alanine concentrations.

\section{MATERIALS AND METHODS}

Animals. All experiments were performed in vivo using adult male albino Sprague-Dawley rats (200-300 g body weight). These animals were obtained from Simonsen Labs (Gilroy, CA) and allowed free access to water and rat food.

Catheters. The portal vein catheter consisted of two $1.5 \mathrm{~cm}$ segments of PE 60 tubing (Clay Adams, Parsippany, NJ; ID 0.76 $\mathrm{mm}$, OD $1.22 \mathrm{~mm}$ ) connected to the ends of a $4.5-\mathrm{cm}$ silastic tube (Dow Corning, Midland, MI; silastic ID $0.64 \mathrm{~mm}$, OD 1.19 $\mathrm{mm})$. The silastic tubing was stretched securely over the segment of PE 60 tubing. The ends of the PE 60 tubing were cut to a sharp point at an angle of approximately $45^{\circ}$. The catheter was then placed over an 8.89-cm 25-gauge spinal needle (Becton Dickinson, Rutherford, $\mathrm{NJ}$ ) which served as an introducer.

The aortic catheter (Fig. 1) consisted of a $2.5-\mathrm{cm}$ segment of silastic tubing (Dow Corning; silastic ID $0.64 \mathrm{~mm}$, OD 1.19 $\mathrm{mm}$ ). A $0.5-\mathrm{cm}$ segment was cut from the tip of a JELCO intravenous catheter placement unit (Critikon, Inc., Tampa, FL) and inserted securely into one end of the silastic tube. A $0.5-\mathrm{cm}$ segment of PE 60 tubing was inserted into the other end of the silastic tube and beveled at $45^{\circ}$, to complete the aortic catheter. The catheter was then placed over the 32-mm 22-gauge JELCO needle which served as an introducer.

The gastric catheter was made by inserting two $0.5-\mathrm{cm}$ segments of PE 60 tubing into the two ends of a $4.5-\mathrm{cm}$ segment of silastic tubing. Another $0.5-\mathrm{cm}$ segment of silastic tubing was then fitted into one end of PE 60 tubing forming the gastric cannula. The end of the remaining PE 60 tube was beveled at $45^{\circ}$.

Operative procedures. Animals were anesthetized with $20 \mathrm{mg} /$ $\mathrm{kg}$ ketamine injected intramuscularly followed by $10 \mathrm{mg} / \mathrm{kg}$ pentobarbital intraperitoneally. The abdomen and back of the neck were shaved, washed with $95 \%$ ethanol, and painted with povodine-iodine $1 \%$ (Betadine). The Betadine was wiped away with alcohol prep pads. Rats were secured in a supine position using gauze ties. All surgical instruments were steam sterilized and the catheters, needles, and a small crochet hook were gas sterilized with ethylene oxide.

Using aseptic technique, a $5-\mathrm{cm}$ vertical midline abdominal incision was made through only the skin from the subxiphoid 


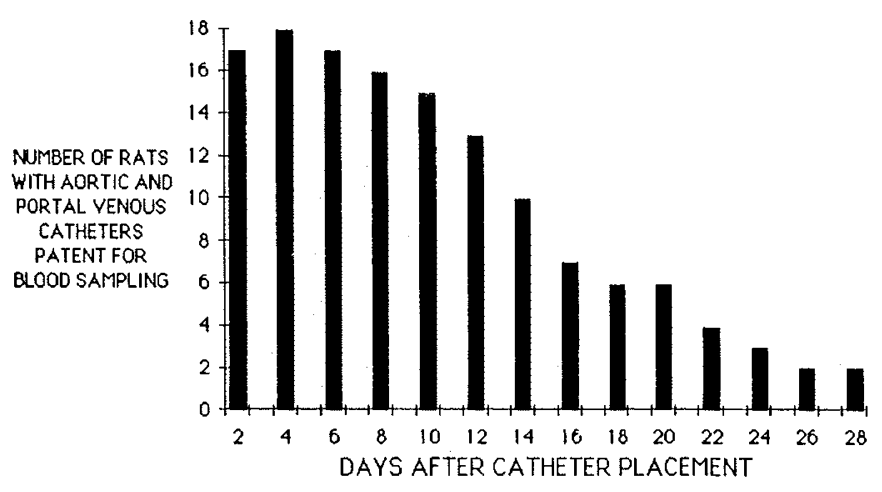

Fig. 1. Number of chronically catheterized rats with aortic and portal venous catheters patent for blood drawing.

process of the sternum to the suprapubic region. The skin was bluntly dissected away from the muscular region on the right side of the abdominal wall. A $0.25-\mathrm{cm}$ skin incision was made over the cervical vertebrae of the rat and a crochet hook was passed subcutaneously from the abdominal incision to the cervical incision. The butterfly needles were removed from three Intermittent Infusion sets (no. 4871, Abbott Hospitals Inc., Chicago, IL). The infusion sets with tubing were flushed with $0.9 \%$ saline solution containing $10 \mathrm{U}$ of heparin $/ \mathrm{ml}$. The infusion set tubes were then pulled through the skin opening in the back and into the abdominal incision through a subcutaneous tunnel made by the crochet hook. The tubes were pulled tightly, bringing the infusion set tubing to the incision on the back. A vertical midline incision, $4.5 \mathrm{~cm}$, was then made through the abdominal wall. The infusion set tubes were introduced into the abdominal cavity through small puncture sites through the right abdominal wall.

The intestine and mesenteric bed were retracted to the left onto sterile gauze sponges (Kendall, Co., Boston, MA) saturated with sterile saline, exposing the portal vein. The portal venous catheter was then introduced into the portal vein just proximal to the liver over the 25-gauge spinal needle. Once the tip of the 25-gauge spinal needle was inserted into the vein, the PE 60 portion of the portal venous catheter was advanced over the needle approximately $1 \mathrm{~cm}$ into the portal vein. After withdrawing the needle, the catheter was secured with a single drop of cyanoacrylate glue (Wonder Bond Plus, Borden Inc. Columbis, $\mathrm{OH})$ as described by Yokota et al. (7). The other PE 60 end of the catheter was inserted into the portal vein infusion set tube. The tube was unclamped and the line was flushed.

To prepare the abdominal aorta for catheterization, the gut was retracted to the left onto sterile gauze soaked in sterile normal saline. Using forceps, the membranous sheath covering the aorta was dissected away. The aortic catheter was introduced into the abdominal aorta just superior to the iliac bifurcation by inserting the tip of the 22-gauge JELCO needle into the aorta and advancing the tip of the JELCO catheter over the 22-gauge JELCO needle into the aorta. After the JELCO tip of the catheter was advanced $0.5 \mathrm{~cm}$ into the aorta, the introducer needle was removed and a drop of cyanoacrylate glue secured the catheter in place. The PE 60 tube end of the catheter was inserted into its infusion set tube. The tube was unclamped from the abdominal wall and the line was flushed.

Once the portal venous and aortic catheters were in place, the gut and mesenteric bed were replaced into the abdominal cavity. The stomach was retracted with forceps and a 4.0 silk suture purse string loop was made through the greater curvature of the stomach wall. A 20 -gauge needle was inserted $3 \mathrm{~mm}$ just through the stomach wall between the loop ties and then removed. The gastric catheter was inserted into the hole to the segment of PE
60 tubing and secured with the purse string suture. The PE 60 tube end of the catheter was connected to the gastric infusion set tubing.

The abdominal wall and skin were each closed with 4.0 silk suture. The infusion sets were sutured securely to the back of the rat using 00 silk suture and glued together using silicone glue to form a single unit. Ampicillin (100 mg/ $\mathrm{kg}$ ) was injected into the portal venous and aortic catheters postoperatively. Daily, after surgery, animals were weighed and the catheters flushed with $0.35 \mathrm{ml}$ of normal saline containing $500 \mathrm{U} / \mathrm{ml}$ heparin and 2.5 $\mathrm{mg} / \mathrm{ml}$ of ampicillin. Surgical placement of these catheters was done within 12 min.

The effect of anesthesia and surgery on portal venous and aortic blood substrate concentrations after an intragastric bolus infusion of glucose. The effects of anesthesia and surgery on portal venous and aortic blood substrate concentrations were investigated in two groups of rats: acutely catheterized (within $1 \mathrm{~h}$ of surgery) and chronically catheterized (more than 10 days after surgery, after regaining preoperative weight). In both groups $10 \mathrm{ml}$ of $0.29 \mathrm{M} d$-glucose were infused into the gastrostomy tube and 0.3 $\mathrm{ml}$ of portal venous and aortic bloods were simultaneously withdrawn from the catheters $0,15,30,45$, and 60 min after the infusion.

Blood samples were immediately placed in $0.4 \mathrm{ml}$ of ice chilled $1 \mathrm{~N} \mathrm{HClO}_{4}$. The weights of the blood samples were measured and the protein precipitate was separated from the remaining solution by centrifugation at $4000 \times g$ for $10 \mathrm{~min}$. The supernatant was then neutralized with $2 \mathrm{M}$ potassium bicarbonate. We adapted spectrophotometric assays for glucose (8), alanine (9), and lactate (10) to fluorometric assays in order to determine substrate concentrations in a small volume of blood. The processing of the blood samples was done within $1 \mathrm{~h}$ of the experiment. Because measuring the weight of the blood samples was more accurate than determining volume, all units of substrate concentration are $\mu \mathrm{mol}$ substrate/g blood.

To determine the plasma clearance rate of indocyanine green, an inferior vena cava catheter, similar to the aortic catheter, was placed in rats with either aortic catheters alone or with both aortic and portal venous catheters. Approximately $3 \mathrm{mg} / \mathrm{kg}$ body weight of indocyanine green was infused into the inferior vena cava and $0.15-\mathrm{ml}$ blood samples were withdrawn at $0,3,6,12$, 18,24 , and $30 \mathrm{~min}$ after the bolus infusion. Indocyanine green concentrations in plasma was determined spectrophotometrically using a wave length of $800 \mathrm{~nm}$ (11). The plasma clearance of indocyanine green was calculated from the indocyanine green concentration versus time curve using the following equation for indocyanine green concentration (12).

$$
\text { indocyanine green concentration }=\mathrm{Ae}^{-\alpha \mathrm{t}}+\mathrm{Be}^{-\beta \mathrm{t}}
$$

and for plasma clearance (12),

$$
\mathrm{Clp}=\operatorname{dose} / \mathrm{AUC}_{\mathrm{iv}}
$$

with $\mathrm{AUC}_{\mathrm{iv}}$ (area aunder the curve)

$$
\mathrm{AUC}_{\mathrm{iv}}=\frac{\mathrm{A}}{\alpha}+\frac{\mathrm{B}}{\beta}
$$

as described by Bowmer et al. (12)

All data are expressed as mean \pm SEM. The statistical significance of differences between samples was assessed using Student's $t$ test with the Bonferroni corrections for multiple $t$ test.

\section{RESULTS}

The chronically catheterized rat preparation. We studied 24 rats in which portal venous and aortic catheters were in place and patent for the withdrawal of blood over a 4-day period. After 10 days, 15 rats had both catheters patent; after 14 days, 10 had both catheters patent and, after 20 days, six had both catheters patent (Fig. 1). 
The body weights of catheterized rats were compared to preoperative weights. The rats lost an average of $10 \%$ of their preoperative weight 3 days after placement of the catheters (Fig. 2). The average weight remained constant for the next 4 days. A steady weight gain of $1.4 \%$ of preoperative weight per day occurred between days 7 and 21 . This weight gain was equal to the growth observed in nonoperated rats $(1.3 \%$ of original weight per day). Preoperative weight was regained in $10.8 \pm 0.7$ days after surgery.

Gross and microscopic examination of the liver after portal venous and aortic catheterization revealed no evidence of emboli in the liver or changes in hepatic blood vessels.

To determine the degree of obstruction by the aortic catheter, we determined aortic blood pressure in a rat with two aortic catheters, one placed at the level of the renal artery and the other superior to the iliac bifurcation. After the catheters were placed surgically (distal catheter first), the laparotomy incision was closed and arterial blood pressure was determined using a transducer and Grass model 79D recorder. Average aortic blood pressure values were similar when measured in both catheters on days 1, 2, 4, and 5 after catheter placement (Table 1). The differences between proximal and distal systolic and diastolic blood pressure were less than $5 \%$ of the mean systolic and diastolic blood pressure (Table 1).

The effect of portal venous catheters on plasma clearance of indocyanine green in chronically catheterized rats. When $3 \mathrm{mg} /$ $\mathrm{kg}$ indocyanine green was infused into the inferior vena cava, the removal of indocyanine green resulted in a decrease in aortic blood concentrations in a pattern previously described (12) (Fig. 3 ). The plasma clearance of indocyanine green in rats with inferior vena cava, portal venous, and aortic catheters was similar to rats with only inferior vena cava and aortic catheters (Table 2 ). The plasma clearance of indocyanine green in rats catheterized for 4 days was similar to the clearance rate in rats catheterized for more than 12 days.

The effect of an intragastric bolus infusion of glucose on portal venous and aortic blood glucose concentrations. In chronically

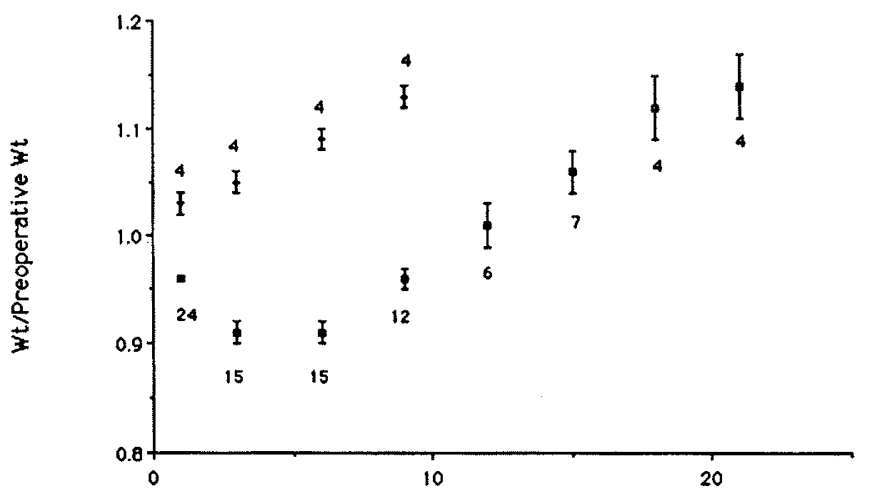

Days after Catheter Placement

Fig. 2. The ratio of postoperative weight/preoperative weight after surgical placement of the catheters. catheterized rats, within $15 \mathrm{~min}$ after the bolus infusion of $d$ glucose into the gastrostomy, aortic blood glucose concentrations reached a maximum concentration of $13.4 \pm 1.3 \mu \mathrm{mol} / \mathrm{g}$ blood (Fig. 4). The mean aortic blood glucose concentration declined to preinfusion concentrations $60 \mathrm{~min}$ after the bolus infusion. In contrast, in acutely catheterized rats, the mean aortic blood glucose concentration continued to increase $60 \mathrm{~min}$ after the glucose infusion. Compared to acutely catheterized rats, the mean aortic blood glucose concentrations of chronically catheterized rats were significantly greater $15 \mathrm{~min}$ after the glucose infusion, but were less 45 and $60 \mathrm{~min}$ after infusion $(p<0.01)$. Mean portal venous blood glucose concentrations of chronically catheterized rats were significantly less than concentrations in acutely catheterized rats 45 and 60 min after the glucose infusion.

The glucose concentration in the aortic blood sample was subtracted from the glucose concentration in the portal venous sample to obtain an estimate of portal venous to aortic concentration difference. In chronically catheterized rats, the portal venous and aortic blood glucose concentrations were not significantly different at any time after the intragastric infusion (Fig. 4). In contrast, in the acutely catheterized rats, the mean portal venous glucose concentration was significantly greater than aortic at $15,30,45$, and $60 \mathrm{~min}$ after the glucose infusion (paired $t$ test, $p<0.01$ ). When compared to the baseline differences (before glucose infusion), the portal venous to aortic blood glucose concentration difference was significantly greater 15 and $30 \mathrm{~min}$ after infusion (paired $t$ test, $p<0.01$ ).

The effect of an intragastric bolus infusion of glucose on portal venous and aortic blood lactate concentrations. The mean aortic blood lactate concentration in chronically catheterized rats increased to a maximum of $1.26 \pm 0.05 \mu \mathrm{mol} / \mathrm{g}$ blood $15 \mathrm{~min}$ after glucose infusion in a pattern similar to the blood glucose concentrations (Fig. 5). Mean aortic blood lactate concentrations declined to $1.02 \pm 0.16 \mu \mathrm{mol} / \mathrm{g}$ blood $60 \mathrm{~min}$ after infusion. In acutely catheterized rats, the aortic blood lactate concentrations continued to increase $60 \mathrm{~min}$ after infusion. The mean blood lactate concentration in acutely catheterized rats was significantly different from the value in chronically catheterized rats 15 and 30 min after infusion $(p<0.01)$.

The mean portal venous lactate concentrations were significantly greater than aortic concentrations 30 and 45 min after the glucose infusion in chronically catheterized rats. In acutely catheterized rats, the mean portal venous lactate concentrations were significantly greater than aortic at $15,30,45$, and 60 min after the glucose infusion. These concentration differences between portal venous and aortic blood lactate were not significantly different from the baseline concentration differences.

The effect of an intragastric bolus infusion of glucose on portal venous and aortic blood alanine concentrations. Mean aortic blood alanine concentrations were not affected by the glucose infusion in either acutely catheterized or chronically catheterized rats (Fig. 6). The mean portal venous alanine concentration was significantly greater than aortic at all times after the glucose infusion (Fig. 6). The magnitude of the difference was not affected by the glucose infusion in either acutely catheterized or chronically catheterized rats.

Table 1. Blood pressure in proximal and distal aortic catheters*

\begin{tabular}{cccccc}
\hline \multirow{2}{*}{$\begin{array}{c}\text { Days after } \\
\text { catheter placement }\end{array}$} & \multicolumn{2}{c}{ Blood pressure (mm Hg) } & & \multicolumn{2}{c}{ Blood pressure difference } \\
\cline { 2 - 3 } \cline { 5 - 6 } & Proximal & Distal & & Systolic & Diastolic \\
\hline 1 & $121 \pm 7 / 100 \pm 7$ & $118 \pm 7 / 98 \pm 7$ & & $3.0 \pm 1.7$ & $1.7 \pm 1.3$ \\
4 & $113 \pm 10 / 83 \pm 17$ & $109 \pm 12 / 80 \pm 16$ & & $4.3 \pm 4.8$ & $3.3 \pm 3.3$ \\
5 & $114 \pm 7 / 95 \pm 6$ & $113 \pm 8 / 94 \pm 7$ & & $1.0 \pm 2.0$ & $1.3 \pm 1.3$ \\
\hline
\end{tabular}

* A proximal catheter was placed through a laparotomy at the level of the renal arteries. A second aortic catheter was placed superior to the iliac bifurcation. After closure of the laparotomy blood pressure was measured through the aortic catheters using a transducer. Values are mean \pm SEM (three rats). 


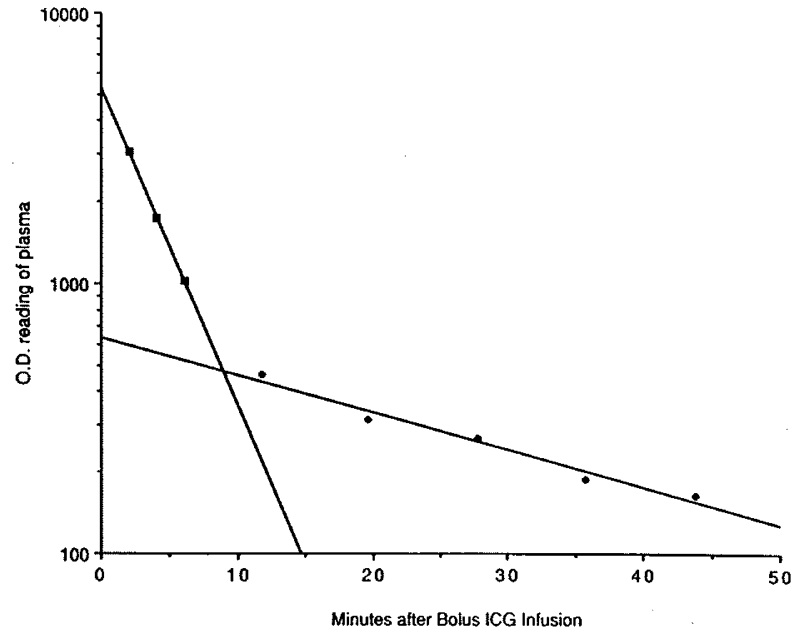

Fig. 3. Changes in plasma indocyanine green concentrations (O.D. at $800 \mathrm{~nm}$ ) after a $3 \mathrm{mg} / \mathrm{kg}$ body weight infusion of indocyanine green.

Table 2. Plasma indocyanine green clearance rates in chronically catheterized rats*

\begin{tabular}{ccc}
\hline Catheters & $\begin{array}{c}\text { Days after } \\
\text { catheter placement }\end{array}$ & $\begin{array}{c}\text { Indocyanine green } \\
\text { clearance }\end{array}$ \\
\hline IVC + A & $6-18$ & $16.6 \pm 2.2(5)$ \\
IVC + PV + A & $4-26$ & $14.6 \pm 1.0(8)$ \\
IVC + PV + A & 4 & $14.1 \pm 0.4(4)$ \\
IVC + PV + A & $12-26$ & $15.2 \pm 2.0(4)$ \\
\hline
\end{tabular}

* Plasma indocyanine green clearance rates were determined in rats with either inferior vena cava and aortic catheters (IVC $+\mathrm{A}$ ) or with inferior vena cava, portal venous, and aortic catheters (IVC $+\mathrm{PV}+\mathrm{A}$ ). Clearance studies were performed 4-26 days after catheter placement.

\section{DISCUSSION}

We have described a new method (13) whereby portal venous and aortic catheters are placed in adult rats by passing the catheters over an introducer needle. Previous techniques of portal venous catheterization have included ligation of fourth generation mesenteric veins (14) or interruption of the portal vein with placement of a $T$ connector into the portal vein $(15,16)$. All other methods for cannulation of the portal vein involve cutting the portal vein and inserting a catheter (17). In each of these techniques, the portal venous blood flow is transiently obstructed. By using an over the needle technique, we have been able to introduce portal venous catheters without obstructing portal venous blood flow. Also, extensive dissection and suture placement are not required and, as a result, the new technique almost certainly is faster.

Portal venous catheters constructed similarly to the aortic catheters with the tip of a 22 JELCO catheter were used initially. These catheters were easier to insert into the portal vein. However, they were not as patent for blood withdrawal as catheters with PE 60 tubing. Because silastic tubing is pliable, movement of the rat and the abdominal contents does not result in movement of the catheter tip in the portal vein or aorta. This results in longer catheter patency.

The insertion of the aortic catheter into the aorta is without blood loss because the hole created by the 22-gauge JELCO needle is smaller than the tip of the JELCO catheter. The JELCO catheter is smaller than the aorta. We believe that cannulation of the aorta using the over the needle technique has enabled us to catheterize the aorta without decreasing vascular perfusion. Using two aortic catheters, we measured no significant difference in arterial blood pressure between the proximal and distal aortic
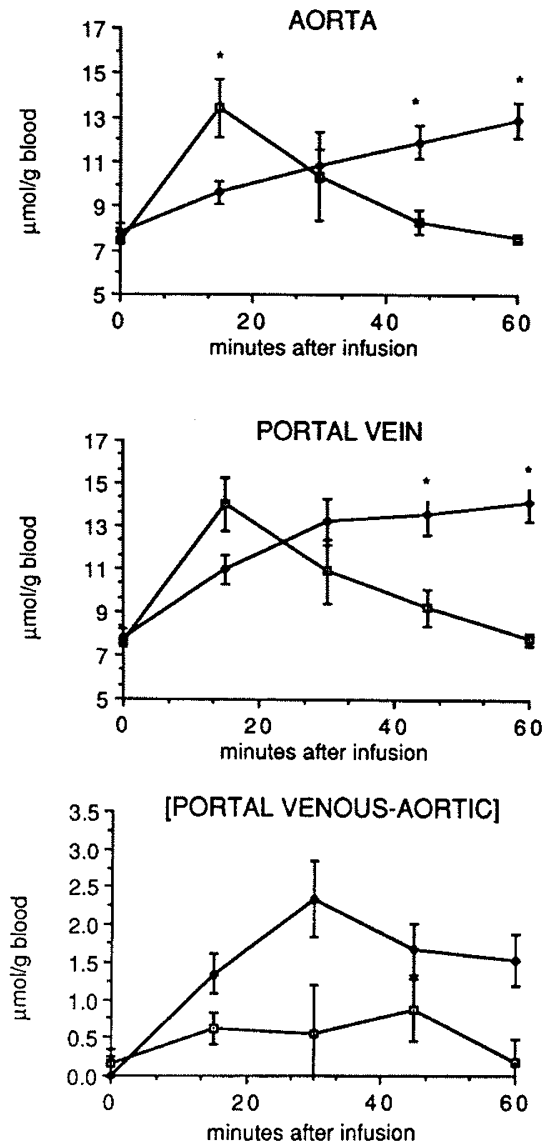

Fig. 4. Changes in aortic and portal venous blood glucose concentrations after a bolus intragastric infusion of $0.29 \mathrm{M} d$-glucose. After surgical placement of portal venous, aortic, and gastric catheters, $10 \mathrm{ml}$ of 0.29 $\mathrm{M} d$-glucose were infused into the gastric catheter in acutely catheterized rats (less than $1 \mathrm{~h}$ after catheter placement, eight rats) or in chronically catheterized rats $\square$ (after the rats had regained preoperative weight, four to five rats). Data are shown as mean \pm SEM. * Values are statistically different from acute $(p<0.012)$.

catheters, suggesting that little resistance was created by the proximal catheter. Using these methods, rats gained weight at a rate comparable to normal controls, suggesting that the catheters do not interfere with nutrition and growth.

Long-term central venous cannulation for blood sampling in rats for as long as $11 \mathrm{wk}$ has been reported $(18,19)$. Tsukamoto et al. (19) used an injection cap to plug the end of the needle that was connected to the central venous catheter. With the use of infusion sets, we were able to connect the portal venous catheter to a single unit. Tsukamoto et al. (19) flushed the central venous catheter twice a week. With our model we found that flushing daily improved the survival of catheter patency for blood sampling. We also determined that the addition of $1 \mathrm{mg}$ of ampicillin $/ \mathrm{ml}$ of flush resulted in prolonged catheter patency. The importance of aseptic technique in catheter placement has been emphasized by Popp and Brennan (20). We speculate that the increase in catheter patency with the addition of ampicillin to the flush is the result of a decreased incidence of septic emboli.

Inasmuch as more than $93 \%$ of indocyanine green is excreted by the liver (11), it has been used as an indicator of liver function and perfusion. There was no significant difference in the plasma clearance of indocyanine green in rats with and without portal venous catheters, indicating that the portal venous catheter does not significantly obstruct liver blood flow or alter liver function. Rats catheterized for more than 12 days had similar plasma clearance of indocyanine green as rats catheterized for 4 days, 

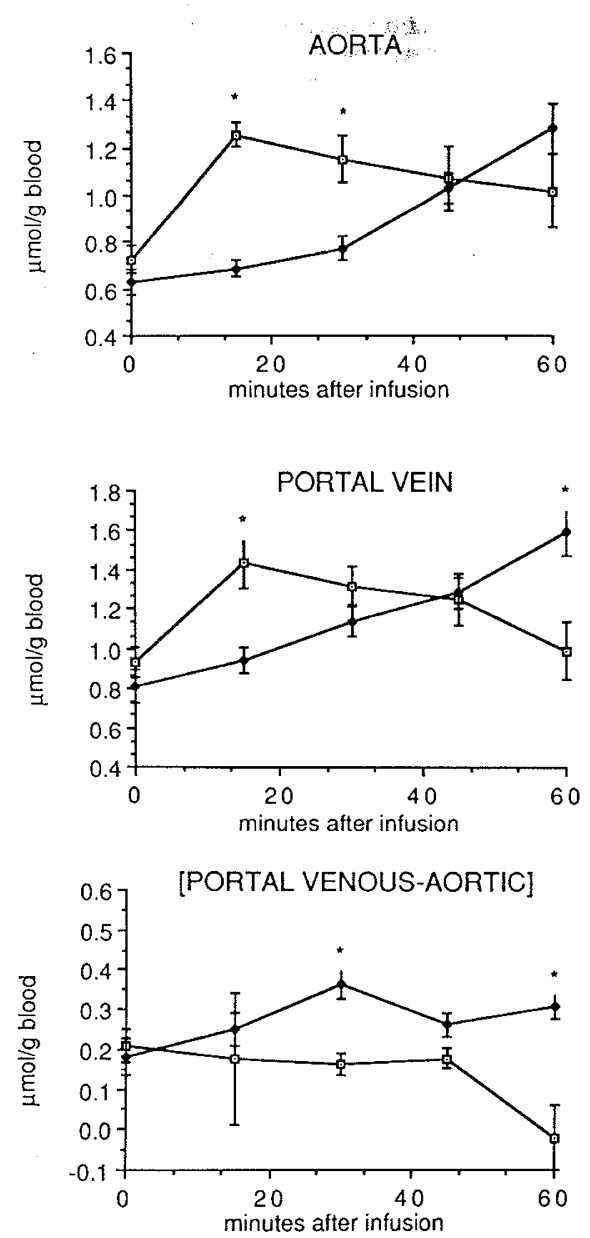

Fig. 5. Changes in aortic and portal venous blood lactate concentrations following a bolus intragastric infusion of $0.29 \mathrm{M} \mathrm{d}$-glucose. After surgical placement of portal venous, aortic, and gastric catheters, $10 \mathrm{ml}$ of $0.29 \mathrm{M} \mathrm{d}$-glucose were infused into the gastric catheter in acutely catheterized rats (less than $1 \mathrm{~h}$ after catheter placement, eight rats) or in chronically catheterized rats $\square$ (after the rats had regained preoperative weight, four to five rats). Data are shown as mean \pm SEM. * Values are statistically different from acute $(p<0.012)$.

suggesting no significant change in portal venous blood flow in rats catheterized for an extended period.

The abrupt increase in aortic blood glucose observed after an intragastric bolus infusion of glucose in the chronically catheterized rats is similar to the finding in chronically catheterized dogs (21). The subsequent decline in blood glucose after a hyperglycemic period observed in the chronically catheterized rats also has been reported in rats (16) and dogs (21). This decline in the blood glucose concentrations probably is secondary to an increase in insulin concentrations after a hyperglycemic period (16, $21,22)$. In acutely catheterized rats, the rise in blood glucose concentrations was not as rapid and a decline in the blood glucose concentration was not present $60 \mathrm{~min}$ after the bolus infusion. This slower rate of increase in blood glucose concentrations may reflect a decreased rate of glucose uptake. The absence of decline of the aortic blood glucose may be secondary to a decrease in insulin response to a blunted rise in blood glucose. Insulin concentrations have not been determined to test this hypothesis. Another possibility for the absence of a decline in glucose concentration after a hyperglycemic period in acutely catheterized rats is the presence of elevated serum glucocorticoids which have been reported in postsurgical rats $(19,23)$. Eigler et al. (24) have shown that glucocorticoids and epinephrine synergistically increase plasma glucose levels. In acutely catheterized rats, the
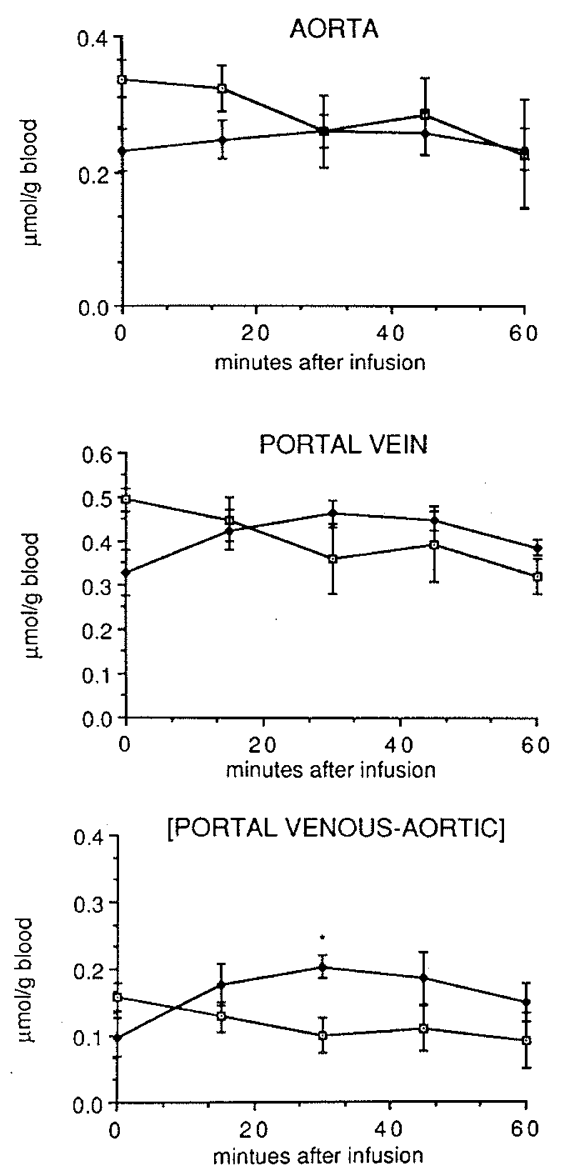

Fig. 6. Changes in aortic and portal venous blood alanine concentrations after a bolus intragastric infusion of $0.29 \mathrm{M} d$-glucose. After surgical placement of portal venous, aortic, and gastric catheters, $10 \mathrm{ml}$ of 0.29 $\mathrm{M} d$-glucose was infused into the gastric catheter in acutely catheterized rats (less than $1 \mathrm{~h}$ after catheter placement, eight rats) or in chronically catheterized rats $\square$ (after the rats had regained preoperative weight, four to five rats). Data are shown as mean \pm SEM. * Values are statistically different from acute $(p<0.012)$.

presence of glucocorticoids and epinephrine may inhibit the decline in glucose concentration after a hyperglycemic period.

In chronically catheterized rats, after an intragastric infusion, a significant portal venous to aortic glucose concentration difference does not appear to exist. However, a 2 -fold increase in blood glucose concentrations rapidly occurs, suggesting significant intestinal absorption of glucose during this period. The low portal venous to aortic glucose concentration gradient may be due to an increase in mesenteric blood flow associated with eating (25-27). The low glucose concentration gradient $(0.68$ $\mu \mathrm{mol} / \mathrm{g}$ blood) measured in chronically catheterized rats is similar to that determined in chronically catheterized dogs $(2.5 \mathrm{mM}$ in plasma) infused with a similar glucose dose (21). The absence of a significant portal venous to aortic glucose concentration gradient is not in agreement with data of Remesy et al. (28) who reported a $5 \mathrm{mM}$ plasma concentration gradient in rats fed a high carbohydrate diet. However, they obtained the aortic and portal venous blood from anesthetized rats through a laparotomy. The glucose concentration gradient that they observed is quantitatively similar to our observations in acutely catheterized rats. Therefore, it is possible that the high glucose gradient described by Remesy et al. (28) was secondary to a decrease in mesenteric blood flow secondary to anesthesia and bowel manipulation.

The changes in lactate concentrations observed are similar to 
the changes in glucose. Increases in aortic blood lactate concentrations after a high carbohydrate diet have been reported previously by Remesy et al. (28). The decline in mean lactate concentrations to baseline levels within $60 \mathrm{~min}$ after an intragastric bolus infusion of glucose in the chronically catheterized rats herein is similar to the decline in aortic blood glucose concentrations and may reflect a decrease in substrate.

Aortic blood alanine concentrations in both acutely catheterized and chronically catheterized rats were not affected by the intragastric glucose infusion. Felig et al. (29) have reported similar findings in humans in which glucose was infused intravenously. The portal venous to aortic blood alanine concentration gradient in chronically catheterized rats was significant before bolus infusion of glucose indicating a net flux of alanine from the intestine. A source of the alanine could be amino acids from absorbed protein or from lactate via alanine aminotransferase, as suggested by Windmueller and Spaeth (2).

Our studies indicate that portal venous and aortic blood substrate concentrations are different in acutely catheterized rats compared to chronically catheterized rats. The effect of anesthesia and bowel manipulation on intestinal function and mesenteric blood flow may have a significant effect on blood glucose and lactate concentrations after a bolus infusion into the gastrostomy. In addition, hormones, such as glucocorticoids, which are increased after surgery, may have significant effects on systemic and intestinal substrate metabolism. Therefore, in situ perfusion studies may not simulate physiologic conditions. The chronically catheterized rat model allows determination of portal venous and aortic blood substrate concentrations in nonstressed animals.

Acknowledgments. The technical assistance of Jasminka Ilich and Jillian Clark is greatly appreciated as well as the assistance in typing the manuscript by Jeanne Ferretti. The authors thank Dr. Robert D. Christensen for his comments.

\section{REFERENCES}

1. Hanson PJ, Parson DS 1976 The utilization of glucose and production of lactate by in vitro preparations of rat small intestine: effects of vascular perfusion. J Physiol 255:775-795

2. Windmueller HG, Spaeth AE 1978 Identification of ketone bodies and glutamine as the major respiratory fuels in vivo for postabsorptive rat small intestine. J Biol Chem 253:69-76

3. Brewster WR, Jr, Bunker JP, Beecher HK 1952 Metabolic effects of anesthesia. VI. Mechanism of metabolic acidosis and hyperglycemia during ether anesthesia in the dog. Am J Physiol 171:37-47

4. Wilkinson CW, Shinsako J, Dallman MF 1981 Return of pituitary-adrenal function after adrenal enucleation or transplantation: diurnal rhythms and responses to ether. Endocrinology 109:162-169

5. Bond JH, Levitt MD 1980 Effect of glucagon on gastrointestinal blood flow of dogs in hypovolemic shock. Am J Physiol 238:G434-G439

6. Meschia G, Makowski E, Battaglia FC 1970 The use of indwelling catheters in the uterine and umbilical veins of sheep for a description of fetal acid-gas balance and oxygenation. Yale J Biol Med 42:154-165

7. Yokota M, Iga T, Awazu S, Hanono M 1976 Simple methods of hepatic venous blood sampling in the rat. J Appl Physiol 41:439-441

8. Shein MW 1965 D-Glucose: determination with hexokinase and glucose-6 phosphate dehydrogenase. In: Bergmeyer HU (ed) Methods of Enzymatic Analysis. Academic Press, New York, pp 117-123

9. Williamson DH 1974 L-Alanine determination with alanine dehydrogenase. In: Bergmeyer HU (ed) Methods of Enzymatic Analysis, 2nd ed., vol 4. Academic Press, New York, pp 1679-1685

10. Hohorst H-J $1965 \mathrm{~L}-(+)$-lactate determination with lactate dehydrogenase and DPN. In: Bergmeyer HU (ed) Methods of Enzymatic Analysis. Academic Press, New York, pp 266-270

11. Burczynski FJ, Pushka KL, Sitar DS, Greenway CV 1987 Hepatic plasma flow: accuracy of estimation from bolus injections of indocyanine green. Am J Physiol 252:H953-H962

12. Bowmer CJ, Yates MS, Emmerson J 1982 The effect of acute renal failure on the pharmacokinetics of indocyanine green in the rat. Biochem Pharmacol 15:2531-2538

13. Cocchetto DM, Bjornsson TD 1983 Methods for vascular access and collection of body fluids from the laboratory rat. J Pharmacol Sci 72:465-492

14. Sloop CH, Krause BR 1981 Portal and aortic blood sampling technique in unrestrained rats. Physiol Behav 26:529-533

15. Gallo-Torres HE, Ludorf J 1974 Techniques for the in vivo catheterization of the portal vein in the rat. Proc Soc Exp Biol Med 145:249-254

16. Sable-Amplis R, Abadie D 1975 Permanent cannulation of the hepatic portal vein in rats. J Appl Physiol 38:358-359

17. Urban E, Zingery AA 1981 A simple method of cannulation of the portal vein and obtaining multiple blood samples in the rat. Experienta 37:1036-1037

18. Burt ME, Arberit J, Brennan MF 1980 Chronic arterial and venous access in the unrestrained rat. Am J Physiol 238:H599-H603

19. Tsukamoto H, Reidelberger RG, French SW, Largman C 1984 Long-term cannulation model for blood sampling and intragastric infusion in the rat. Am J Physiol 247:R595-R599

20. Popp MB, Brennan MF 1981 Long-term vascular access in the rat: importance of asepsis. Am J Physiol 241:H606-H612

21. Abumrad NN, Cherrington AD, Williams PE, Lacy WW, Rabin D 1982 Absorption and disposition of a glucose load in the conscious dog. Am J Physiol 242:E398-E406

22. Steele R, Bjerknes C, Rathgeb I, Altszuler N 1982 Glucose uptake and production during the oral glucose load in the conscious dog. Am J Physiol 242:E398-E406

23. Fagin KD, Shinsako J, Dallman MF 1983 Effects of housing and chronic cannulation on plasma ACTH and corticosterone in the rat. Am $\mathrm{J}$ Physiol 245:E515-E520

24. Eigler N, Sacca L, Sherwin RS 1979 Synergistic interactions of physiologic increments of glucagon, epinephrine, and cortisol in the dog. J Clin Invest 63:114-123

25. Bond JH, Prentiss RA, Levitt MD 1979 The effects of feeding on blood flow to the stomach, small bowel and colon of the conscious dog. J Lab Clin Med 93:594-599

26. Felig P, Wahren J, Hendler R 1975 Influence of oral glucose ingestion on splanchnic glucose and gluconeogenic substrate metabolism in man. Diabetes 24:468-475

27. Szabo JS, Mayfield SR, Oh W, Stonestreet BS 1987 Postprandial gastrointestinal blood flow and oxygen consumption: effect of hypoxemia in neonatal piglets. Pediatr Res 21:93-98

28. Remesy C, Demigne C, Aufrere J 1978 Inter-organ relationships between glucose, lactate and amino acids in rats fed on high-carbohydrate or highprotein diets. Biochem J 170:321-329

29. Felig P, Owen OE, Wahren J, Cahill GF Jr 1969 Amino acid metabolism during prolonged starvation. J Clin Invest 48:584 